\title{
Pharmacologic therapy for inflammatory bowel disease refractory to steroids
}

This article was published in the following Dove Press journal:

Clinical and Experimental Gastroenterology

17 August 2015

Number of times this article has been viewed

\section{MP Martínez-Montiel \\ B Casis-Herce \\ GJ Gómez-Gómez \\ A Masedo-González \\ C Yela-San Bernardino \\ C Piedracoba \\ G Castellano-Tortajada}

Division of Gastroenterology, Hospital 12 de Octubre, Madrid, Spain
Correspondence: MP Martínez-Montiel Division of Gastroenterology, Hospital 12 de Octubre, Madrid 2804I, Spain Tel +34 9l 7792667

Email eiintestinal.hdoc@salud.madrid.org

\begin{abstract}
Although corticosteroids are an effective treatment for induction of remission in inflammatory bowel disease (IBD), many patients are dependent on or refractory to corticosteroids. This review is based on scrutinizing current literature with emphasis on randomized controlled trials, meta-analyses, and Cochrane reviews on the management of IBD refractory to corticosteroids. Based on this evidence, we propose algorithms and optimization strategies for use of immunomodulator and biologic therapy in IBD refractory to corticosteroids.
\end{abstract}

Keywords: immunomodulators, anti-tumor necrosis factor alpha, Crohn's disease, ulcerative colitis, drug levels, treatment optimization

\section{Introduction}

The etiology of Crohn's disease (CD) and ulcerative colitis (UC) is not clear, and no curative therapy is therefore available. At present, the aim of treatment for inflammatory bowel disease (IBD) is to achieve mucosal healing, which is associated with fewer admissions to hospital and surgeries, and better patient quality of life. ${ }^{1-3}$ Deep remission, defined as the absence of symptoms, markers of inflammatory activity, and endoscopic lesions, is a proposed treatment objective in clinical trials. ${ }^{4}$ Conventional treatment with corticosteroids and immunomodulators (IMMs, step-up strategy) has not been able to reduce the complications of the disease or modify its course. ${ }^{5}$ The top-down approach (comprising biologic treatment from the time of diagnosis) is not without side effects, is expensive, and implies overtreatment of patients with milder IBD. ${ }^{6,7}$ At present, the accelerated step-up approach (early introduction of IMM and biologic agents in patients with more serious disease) is probably the most widely accepted management strategy. ${ }^{7}$ Studies are needed to identify universally accepted indicators of poor prognosis, with a view to individualizing therapy according to patient risk and efficacy of drugs (treat-to-target strategy). The present review addresses the concept and management of IBD refractory to corticosteroid therapy in the routine clinical practice setting.

\section{Refractory IBD}

Corticosteroids are very effective in controlling acute flare-ups of IBD, but $16 \%$ of patients fail to respond to such drugs, and $20 \%-30 \%$ show only a partial response. ${ }^{8}$ IBD refractory to corticosteroids includes corticosteroid-dependent patients. According to the current guides, ${ }^{9,10}$ refractory IBD is defined as active disease despite full-dose prednisolone $(0.75 \mathrm{mg} / \mathrm{kg} /$ day $)$ for 4 weeks. This period could be shortened in future, 
as a threshold prior to introduction of biologic treatment. Corticosteroid-dependent IBD is defined as: inability to lower prednisolone to $<10 \mathrm{mg}$ /day for keeping IBD inactive for 3 months or as relapse within 3 months or less after suspending corticosteroid treatment. In severe flare-ups of $\mathrm{UC}$, the response to intravenous corticosteroids is evaluated on the third day, since the seriousness of the condition requires rapid management.

Before diagnosing a patient as having IBD refractory to corticosteroids, we must confirm the activity of the disease and eliminate possible causes of false refractoriness. In the case of $\mathrm{CD}$, we must rule out complications (eg, abscesses) using imaging techniques. In patients with UC, we must exclude added infections (eg, Clostridium difficile and cytomegalovirus) and rule out colorectal cancer., ${ }^{9,10}$ The rescue treatment of choice in IBD refractory to corticosteroids depends on the extent and severity of the disease, and on clinical prognosis factors.

\section{Immunosuppressors \\ Thiopurines}

Azathioprine and 6-mercaptopurine are IMMs with complex metabolism involving participation of various enzymes. Thiopurine-S-methyltransferase (TPMT) plays a determining role in drug metabolism. The 6-thioguanine nucleotides are responsible for the efficacy of these drugs and also for their bone marrow toxicity. The 6-methylmercaptopurine metabolites have been related to possible inefficacy of the medication and to liver toxicity and gastrointestinal intolerance. ${ }^{11}$ At present, the usefulness of determination of TPMT activity is questionable, although it is cost-effective in clinical practice. ${ }^{11}$ Treatment can be started accordingly with the TPMT, if it is known (Figure 1). Thiopurines are slow-acting drugs, and it may take 6 months to obtain therapeutic effects.

\section{Efficacy in CD}

The efficacy of thiopurines in the treatment of active CD is controversial, according to the results of meta-analyses. ${ }^{12,13}$ At present, thiopurines are not recommended as monotherapy for inducing remission of active CD; rather, they should be combined with corticosteroids or anti-tumor necrosis factor alpha (TNF $\alpha$ ) agents until remission is achieved. ${ }^{12}$ Thiopurines are effective in maintaining remission of $\mathrm{CD}$, are able to lessen the need for corticosteroids (number needed to treat $[\mathrm{NNT}] 3$ ), and reduce the need for surgery by $40 \%{ }^{14}$ Azathioprine and 6-mercaptopurine are effective in achieving mucosal healing in CD, and the effect seems to be better in the colon than in the ileum (70\% versus 54\%). ${ }^{15}$
Table I Adverse effects of immunomodulators

\begin{tabular}{|c|c|c|}
\hline Drug & Type of adverse events & $\begin{array}{l}\text { Percentage } \\
\text { of patients }\end{array}$ \\
\hline \multirow[t]{5}{*}{ AZA/6-MP } & $\begin{array}{l}\text { Allergic reactions: malaise, rash, } \\
\text { fever, pancreatitis, hepatitis }\end{array}$ & $5-10$ \\
\hline & $\begin{array}{l}\text { Bone marrow suppression: } \\
\text { leukopenia }\end{array}$ & $2-15$ \\
\hline & Infections & $0.3-7.4$ \\
\hline & $\begin{array}{l}\text { Liver toxicity (cholestasis, } \\
\text { endothelial damage, portal } \\
\text { hypertension, hepatic peliosis, } \\
\text { venous occlusion) }\end{array}$ & $3-10$ \\
\hline & $\begin{array}{l}\text { Malignancies (lymphomas, non- } \\
\text { melanoma skin cancer, leukemia, } \\
\text { cervical cancer) }\end{array}$ & $\begin{array}{l}\text { Lymphoma } \\
\text { (OR 2-4.18) }\end{array}$ \\
\hline \multirow[t]{6}{*}{ MTX } & Digestive intolerance & 13 \\
\hline & Pneumonitis & 2.7 \\
\hline & Bone marrow toxicity & 3 \\
\hline & Liver enzyme alterations & 10 \\
\hline & Liver fibrosis & 5 \\
\hline & Teratogenicity & 100 \\
\hline \multirow[t]{8}{*}{ CsA } & Hypertension & $15-30$ \\
\hline & Nephrotoxicity & 5 \\
\hline & Seizures & 4 \\
\hline & Headache & 20 \\
\hline & Paresthesias & 50 \\
\hline & Tremor, muscle pain & $10-15$ \\
\hline & Infections & $6-15$ \\
\hline & $\begin{array}{l}\text { Hypomagnesemia/ } \\
\text { hypercholesterolemia }\end{array}$ & $30-40$ \\
\hline \multirow[t]{5}{*}{ Tacrolimus } & Hypertension, hyperglycemia & $2-3$ \\
\hline & Paresthesias, tremor, headache & $10-30$ \\
\hline & Renal failure (generally reversible) & $6-14$ \\
\hline & Gastrointestinal intolerance & $7-50$ \\
\hline & Opportunistic infections & 8 \\
\hline \multirow[t]{2}{*}{ MMF } & Diarrhea & 30 \\
\hline & $\begin{array}{l}\text { Histological changes similar } \\
\text { to those of graft versus host } \\
\text { disease }\end{array}$ & \\
\hline \multirow[t]{2}{*}{ Thalidomide } & Neurological toxicity (neuropathy) & $30-50$ \\
\hline & Teratogenicity & 100 \\
\hline
\end{tabular}

Abbreviation: AZA, azathioprine; 6-MP, mercaptopurine; MTX, methotrexate; CsA, cyclosporine, MMF, Mycophenolato mofetil. OR, odds ratio.

\section{Efficacy in UC}

Thiopurines are not recommended for inducing remission of UC, probably because of the late onset of action of these drugs. ${ }^{16}$ Azathioprine is better than mesalazine for achieving remission in patients with corticosteroiddependent UC. ${ }^{17}$ Thiopurines are effective in maintaining remission of UC. A meta-analysis found the efficacy of azathioprine/6-mercaptopurine in maintenance therapy to 
be $76 \%$, with an absolute reduction in relapse risk of $23 \%$ (NNT 5). ${ }^{18}$ Thiopurines have been shown to be effective in maintaining the remission induced by cyclosporine. ${ }^{10}$ The risk of colectomy in UC patients treated with thiopurines is $10 \%$ in the 29 months following the start of therapy. Use of thiopurines for 12 months reduced this risk by $71 \% .^{19}$

\section{Safety}

Thiopurines give rise to adverse events in $26 \%$ of cases (Table 1), and such events require drug suspension in $17 \%$ of patients. Surveillance of possible adverse events during treatment are therefore required. ${ }^{9,10,20}$ Infections are among the most important problems. Herpes infections and disseminated Epstein-Barr virus infections are related to the lymphopenia $(<600$ per $\mu \mathrm{L})$ induced by these drugs. ${ }^{21}$ An increased risk of lymphoma has been described in patients on thiopurines, attributable to the medication, severity of the disease, or both. A meta-analysis of 18 studies concluded that IBD patients treated with thiopurines have an increased risk of lymphoma (odds ratio 4.49; 95\% confidence interval [CI] 2.18-7.17), in particular after 1 year of exposure and in males younger than 30 years. ${ }^{22}$ Lymphoma may be associated with Epstein-Barr virus infection in patients with IBD. As a result, young seronegative males are regarded as a risk group for treatment with thiopurines, and in such individuals treatment with methotrexate and/or anti-TNF $\alpha$ agents should be considered. ${ }^{23}$ There have been reports of hepatosplenic T-cell lymphoma, a fatal disease, in young males with IBD who have received thiopurines in monotherapy and associated with anti-TNF $\alpha$ drugs. ${ }^{24}$ Therefore, despite the efficacy of combination treatment (anti-TNF $\alpha$ and thiopurines), monotherapy must be considered after 2 years of treatment. Thiopurines increase the risk of non-melanoma skin cancer even after treatment suspension.
Photoprotective measures and annual dermatologic checks are therefore advised. ${ }^{24} \mathrm{An}$ increased risk of cervical cancer has been described in women with IBD subjected to treatment with thiopurines (particularly in CD). ${ }^{24}$ Azathioprine and 6-mercaptopurine are safe during pregnancy, and do not increase the risk of perioperative complications in IBD. ${ }^{10}$

\section{Optimization of therapy}

Switching to 6-mercaptopurine in patients with digestive intolerance to azathioprine is effective in $69 \%$ of cases, but is less useful with other adverse events (leukopenia), and is not recommended in the presence of pancreatitis..$^{10}$ Dose splitting reduces the levels of 6-methylmercaptopurine metabolites and thus also the liver toxicity and flu syndrome. Determination of TPMT, 6-thioguanine nucleotide, and 6-methylmercaptopurine levels may be useful for optimizing treatment (Figure 1). ${ }^{25}$ Patients who do not tolerate full-dose thiopurines in monotherapy, with preferential metabolization toward 6-methylmercaptopurine may benefit from the combination of allopurinol (100 mg/day). There would be a reduction of $25 \%-50 \%$ in the thiopurine dose however, to avoid toxicity". 25

Thiopurines have synergistic effects with anti-TNF $\alpha$ drugs and lessen their immunogenicity of biological therapy. Combination therapy is therefore recommended, since it results in greater efficacy, with less risk of loss of response due to production of antibodies against the anti-TNF $\alpha$ molecules. ${ }^{26}$ Suspension of thiopurines may be considered on an individualized basis and in selected patients who have been in deep remission for over 5 years. ${ }^{25,27}$

\section{Thioguanine}

Evidence for the use of thioguanine in IBD is low. Liver toxicity (nodular regenerative hyperplasia) has limited the use of

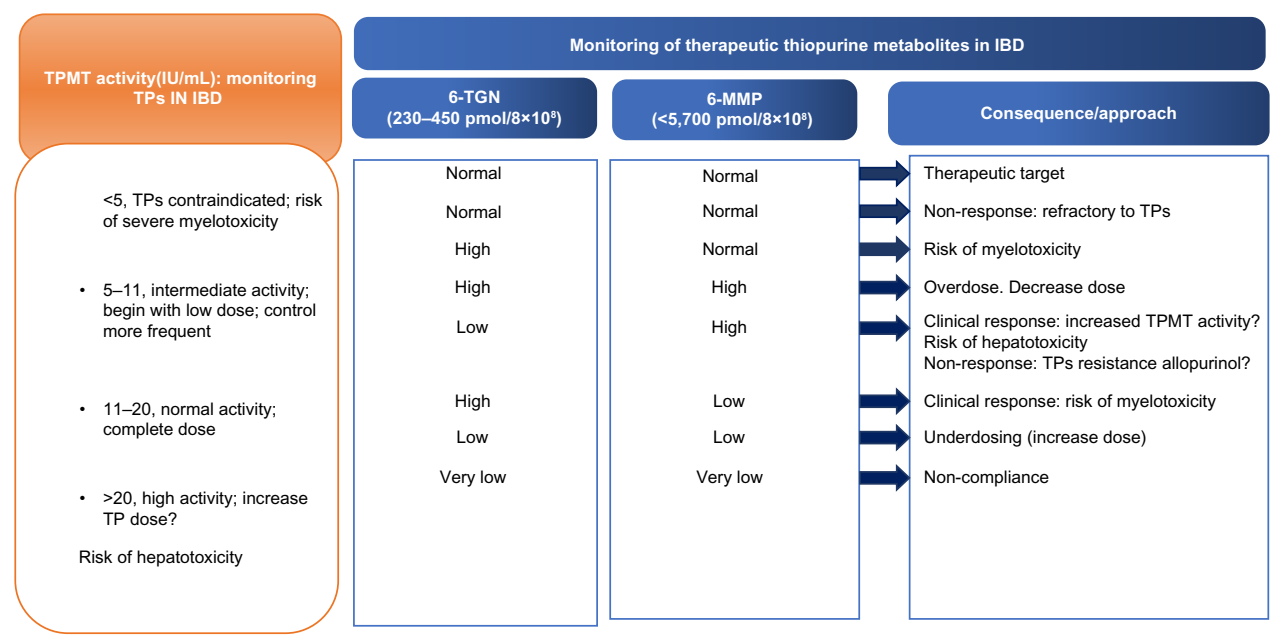

Figure I Optimizing thiopurines.

Abbreviations: IBD, inflammatory bowel disease; 6-TGN, 6-thioguanine; 6-MMP, 6-methylmercaptopurine; TP, thiopurine; TPMT, thiopurine-S-methyltransferase. 
this drug, and it is presently not recommended as a treatment for IBD. Low-dose thioguanine (10-20 mg) could be effective and safe for short periods in IBD patients who do not tolerate or are refractory to azathioprine/6-mercaptopurine. ${ }^{28}$

\section{Methotrexate}

Methotrexate is the second-line IMM option in CD in situations of failure or intolerance to thiopurines $30 \%$ of patients) and in arthropathy associated with IBD. ${ }^{9,29}$ The drug appears to have less bioavailability when administered via the oral route than when given intravenously. ${ }^{29}$ The latency period is 6-8 weeks, so concomitant treatment with corticosteroids is required at the start of therapy.

\section{Efficacy in CD}

A recent Cochrane review found parenteral methotrexate ( $25 \mathrm{mg} /$ week) to be effective in inducing remission and when withdrawing corticosteroids in active CD (NNT 5). ${ }^{30}$ Recent reviews and controlled studies indicate that parenteral methotrexate ( $15 \mathrm{mg} /$ week) is effective versus placebo in maintaining remission in quiescent $\mathrm{CD}(65 \%$ versus $39 \% ; P=0.04$; NNT 4). However, oral methotrexate (12.5-15 mg/week) is not effective versus placebo in maintaining CD remission $(90 \%$ versus $67 \%$ ). ${ }^{31}$ On comparing methotrexate versus azathioprine in corticosteroid-dependent $\mathrm{CD}$, efficacy with regard to ability to withdraw corticosteroids was found to be similar for both drugs (methotrexate $56 \%$, azathioprine $63 \%$; $P=0.39$ ). ${ }^{32}$

\section{Efficacy in UC}

In a systematic review, methotrexate was not effective in inducing remission of active $\mathrm{UC}$, although it may reduce steroids use in one-third of patients and may be beneficial in those who are refractory or intolerant to thiopurines. ${ }^{28}$

\section{Safety}

The incidence of adverse events with methotrexate is $20 \%$, and in $30 \%$ of cases the drug is suspended after 5 years of follow$u^{33}$ (Table 1). Five percent of patients require suspension of methotrexate because of liver problems, particularly those with previous liver disease. Cumulative doses of 3-5 g appear to be safe in $\mathrm{CD}$, and a liver biopsy is only recommended in the event of persistent changes in liver function tests. ${ }^{16,33}$

Methotrexate is teratogenic. Its use during pregnancy is contraindicated, and women who wish to have children must stop the medication 3-6 months before planning pregnancy. ${ }^{9,29}$ Methotrexate is not associated with development of tumors in IBD, and therefore might be indicated in patients with neoplasms who require IMM therapy. ${ }^{28}$

\section{Optimization of therapy}

Methotrexate is effective in cases where thiopurines have failed. Consequently, before accepting failure of IMM treatment in IBD, use should be made of methotrexate. ${ }^{28}$ Given the lower risk of lymphoma during treatment with methotrexate in IBD patients, Epstein-Barr virus-seronegative individuals, particularly young males, might benefit from methotrexate instead of thiopurines. ${ }^{23,28,29}$ The role of methotrexate in combination with biologic agents has not been well established. In the COMMIT study, a combination of infliximab + methotrexate was not found to be superior to infliximab as monotherapy. ${ }^{34}$ However, methotrexate reduces the immunogenicity of infliximab, and this might contribute to the recovery of response to the biologic agent. ${ }^{34}$

\section{Calcineurin inhibitors Cyclosporine}

Controlled studies have demonstrated the efficacy of intravenous cyclosporine ( $4 \mathrm{mg} / \mathrm{kg} /$ day) in the management of severe UC refractory to corticosteroids $(64 \%-80 \%)$, with a mean time to response of 2-7 days. In clinical practice, an intravenous dose of $2 \mathrm{mg} / \mathrm{kg}$ is equally effective and causes lesser toxicity. ${ }^{10,35}$ The clinical response should be evaluated within the first 48-72 hours. The drug requires adjustment according to serum levels (150-200 mg/mL), which limits its use. Once the response has been induced via the intravenous route, azathioprine/6-mercaptopurine is introduced in patients naïve to thiopurines. ${ }^{10}$ Despite the initial benefit obtained, over $50 \%$ of responders to intravenous cyclosporine will require colectomy in the next 3-7 years. ${ }^{35}$ Rescue treatment with cyclosporine does not increase the postoperative complications. ${ }^{36}$

Cyclosporine and infliximab show similar response rates with regard to induction of remission in patients with severe flare-ups of UC refractory to corticosteroids (80\%), and there are no differences between these drugs in terms of the colectomy rate after 3 or 12 months. The choice of one drug or the other depends on patient comorbidity, the experience of the center, the availability of cyclosporine level determinations, and cost. ${ }^{37}$ Sequential therapy with infliximab after failure of cyclosporine is not advised until conclusive data are obtained, in view of the risk of complications, particularly infection. ${ }^{35}$

A systematic review concluded that cyclosporine via the oral route $(5 \mathrm{mg} / \mathrm{kg} /$ day) was not effective in inducing remission of CD in patients refractory to corticosteroids. ${ }^{38}$

Cyclosporine is associated with numerous adverse events, most of which are dose-related (Table 1). Low cholesterol levels $(<110 \mathrm{mg} / \mathrm{dL})$ increase the frequency of adverse events. Opportunistic infections (3.5\%) are among the most serious 
complications of cyclosporine treatment, particularly those caused by Pneumocystis jiroveci. Chemoprophylaxis with trimethoprim-sulfamethoxazole is therefore recommended in the event of triple IMM therapy. ${ }^{21}$ The drug is not adequate for use in cases of thiopurine intolerance or failure..$^{10,33}$

\section{Tacrolimus}

Tacrolimus is a calcineurinic IMM with functions similar to those of cyclosporine, but with a more predictable adverse event profile. Tacrolimus has been used in refractory UC. ${ }^{10,35}$ Following induction of remission with tacrolimus, maintenance therapy should be started with thiopurines in naïve patients. ${ }^{35}$ Tacrolimus has been used via the rectal route in proctitis refractory proctitis, with promising results. ${ }^{28}$ Further controlled studies are needed to confirm the efficacy and safety of tacrolimus in patients with $\mathrm{CD} .{ }^{39}$ The main limitations to use of tacrolimus are the need to determine therapeutic levels and the adverse events (Table 1).

\section{Other immunosuppressors Mycophenolate mofetil}

Mycophenolate is not recommended for the treatment of IBD refractory to corticosteroids, although it could constitute an alternative in patients who fail to tolerate thiopurines, possibly affording a greater effect in UC. ${ }^{40}$ Adverse events related to mycophenolate mofetil are seen in $20 \%-30 \%$ of patients (Table 1).

\section{Thalidomide}

At present, thalidomide is only recommended in active CD refractory to IMM and biologic drugs. ${ }^{41}$ There is no evidence warranting use of thalidomide in refractory UC. Side effects may limit long-term use (Table 1). The drug is teratogenic and effective contraceptive methods must be used.

\section{Biologic agents}

Biologic agents used in the treatment of IBD include monoclonal antibodies against key targets in the intestinal inflammatory process (Table 2).

\section{TNF $\alpha$ antibodies}

The anti-TNF $\alpha$ agents used in IBD are infliximab, adalimumab, certolizumab, and golimumab. Infliximab was the first antiTNF $\alpha$ agent approved for the treatment of CD. ACCENT-I ${ }^{4}$ and ACCENT-II ${ }^{42}$ demonstrated the efficacy of infliximab in maintenance of remission achieved after the initial response, the safety profile of the drug, and the optimum doses and posology. ACCENT-I showed that scheduled treatment was more effective than sporadic treatment, and suggested a greater probability of mucosal healing, with fewer hospital admissions. ${ }^{43}$

CLASSIC-I ${ }^{44}$ demonstrated that adalimumab was superior to placebo in terms of inducing remission of active $\mathrm{CD}$, and the $160 / 80 \mathrm{mg}$ dose was found to be the most effective. CLASSICII showed adalimumab at doses of $40 \mathrm{mg}$ every 2 weeks to be effective in maintaining disease remission until week $56 .{ }^{45}$ $\mathrm{CHARM}^{46}$ and EXTEND ${ }^{47}$ demonstrated the efficacy of adalimumab in long-term maintenance therapy (with $30 \%$ of patients in remission after 4 years). GAIN is the first study to evaluate the efficacy of a second anti-TNF $\alpha$ drug in patients who do not tolerate or lose response to infliximab. ${ }^{48}$ In week 4 , the remission was $21 \%$ in patients on adalimumab and $7 \%$ in those on placebo $(P<0.001)$.

Controlled studies of certolizumab (PRECISE 1-4) involving 1,891 patients revealed the efficacy of certolizumab

Table 2 Drugs, doses, formulations, regimens, and half-life of biologic therapy

\begin{tabular}{|c|c|c|c|c|}
\hline Drug & Dosage form & Pharmaceutical presentation & Dose and schedule & Half-life \\
\hline \multirow[t]{3}{*}{ Infliximab (Remicade ${ }^{\circledR}$ ) } & Intravenous & Vial $100 \mathrm{mg}$ & Induction: $5 \mathrm{mg} / \mathrm{kg}$ at $0 / 2 / 6$ weeks & 7.7-9.5 days \\
\hline & & & Maintenance: every 8 weeks & \\
\hline & & & Induction: $5-10 \mathrm{mg} / \mathrm{kg}, 6-4$ weeks & \\
\hline \multirow[t]{3}{*}{ Adalimumab (Humira ${ }^{\circledR}$ ) } & Subcutaneous & Drug pen $40 \mathrm{mg}$ & Induction: $160 / 80 / 40 \mathrm{mg}$ at $0 / 2 / 4$ weeks & 2 weeks \\
\hline & & & Maintenance: $40 \mathrm{mg} / \mathrm{I} 5$ days & (10-20 days) \\
\hline & & & Induction: 40 mg/every other week & \\
\hline \multirow[t]{3}{*}{ Golimumab (Simponi ${ }^{\circledR}$ ) } & Subcutaneous & Drug pen $50 \mathrm{mg}$ & Induction $200 / 100 \mathrm{mg}$ at $0 / 2$ weeks & 2 weeks \\
\hline & & & Maintenance: $<80 \mathrm{~kg} 50$ mg/4 weeks & \\
\hline & & & $\geq 80 \mathrm{~kg} 100 \mathrm{mg} / 4$ weeks & \\
\hline \multirow[t]{2}{*}{ Certolizumab (Cimzia $\left.{ }^{\circledR}\right)$} & Subcutaneous & Drug pen 200 mg & Induction: $400 \mathrm{mg}$ at 0/2/4 weeks & I4 days \\
\hline & & & Maintenance: 400 mg/4 weeks & \\
\hline Ustekinumab (Stelara ${ }^{\circledR}$ ) & Subcutaneous & Drug pen 45 mg & Not defined in CD & 21.6 days \\
\hline \multirow[t]{2}{*}{ Vedolizumab (Entyvio ${ }^{\circledR}$ ) } & Intravenous & Vial $300 \mathrm{mg}$ & Induction: $300 \mathrm{mg}$ at $0 / 2 / 6$ weeks & 6 weeks \\
\hline & & & Maintenance: 8 weeks & \\
\hline
\end{tabular}

Abbreviation: $C D$, Crohn's disease. 
at a dose of $400 \mathrm{mg}$ in the induction and maintenance of moderate to severe CD. ${ }^{49}$ Two meta-analyses concluded that certolizumab may be an efficacious and safe treatment for $\mathrm{CD}$ as maintenance therapy. ${ }^{50}$ Certolizumab shows significant efficacy versus placebo in patients who had lost response to infliximab or who failed to tolerate this drug. ${ }^{51}$ All anti-TNF $\alpha$ drugs are more effective than placebo in achieving mucosal healing. ${ }^{43,47,49}$

\section{Comparative efficacy}

All the anti-TNF $\alpha$ drugs neutralize the action of TNF $\alpha$, although their structure, mechanism of action, pharmacokinetics, and pharmacodynamics differ, a fact that may have implications regarding their therapeutic efficacy. No significant differences have been observed between the drugs, although a greater induction response rate was seen with infliximab, while adalimumab proved superior in terms of maintenance therapy. Among the subcutaneous anti-TNF $\alpha$ drugs, adalimumab was superior to certolizumab in inducing remission (relative risk 2.93; 95\% CI 1.21-7.75)..$^{51}$

\section{Efficacy in UC}

The ACT-I and ACT-II trials showed the efficacy of infliximab in the treatment of UC refractory to at least one standard drug. ${ }^{52}$ The two studies had a similar design and both showed that infliximab is significantly superior $(P<0.001)$ to placebo in moderate to severe UC refractory in terms of induction of clinical response and remission. Infliximab was superior to placebo in inducing clinical remission (relative risk 3.22; 95\% CI 2.18-4.76) and endoscopic remission (relative risk 1.8; 95\% CI 1.54-2.28) in patients with moderate to severe UC refractory to steroids. ${ }^{53}$

Järnerot et al compared the efficacy of a single $5 \mathrm{mg} / \mathrm{kg}$ dose of infliximab versus placebo for severe flare-ups of UC refractory to corticosteroids. ${ }^{54}$ The results showed statistically significant superiority of infliximab in controlling flare-ups and in terms of the colectomy rates $(29 \%$ for infliximab versus $67 \%$ for placebo) after 1 and 3 months.

ULTRA-1 and ULTRA-2 demonstrate the efficacy of adalimumab in induction of remission and maintenance of remission in moderate to severe UC exhibiting inadequate response to conventional treatments. ${ }^{55,56}$ At week 8 in ULTRA-1, patients who received the dose of 160/80/40 mg showed a significantly greater remission rate than those given placebo ( $18.5 \%$ versus $9.2 \% ; P=0.031)$.

ULTRA-2 included 494 patients with moderate to severe UC who were unresponsive to corticosteroids and IMM. Of these individuals, $40.3 \%$ had previously received
anti-TNF $\alpha$ therapy, which was found to be more effective than placebo in securing disease remission at both week 8 (16.5\% versus $9.3 \% ; P=0.02)$ and week $52(17.3 \%$ versus $8.5 \% ; P=0.01)$. Patients naïve to anti-TNF $\alpha$ agents showed higher remission rates in weeks 8 and $52(21.3 \%$ and $22 \%$, respectively).

Golimumab is the newest anti-TNF $\alpha$ drug approved for the treatment of moderate-severe UC. The Phase III PURSUIT-SC study ${ }^{57}$ concluded that treatment containing subcutaneous golimumab resulted in a clinical response rate of $51 \%-56 \%$ at week 6 versus $30.3 \%$ in the placebo group ( $P \leq 0.0001)$. The PURSUIT-M study concluded that a total of $47 \%$ and $49.7 \%$ of those treated with golimumab $50 \mathrm{mg}$ and $100 \mathrm{mg}$, respectively, via the subcutaneous route every 4 weeks, maintained their clinical response in week 54, versus $31.2 \%$ in the placebo group $(P=0.010$ and $P<0.001) .{ }^{58}$ In weeks 30 and 54, those who had received the $100 \mathrm{mg}$ dose of golimumab showed higher clinical remission $(27.8 \%)$ and mucosal healing rates $(42.4 \%)$ versus placebo $(15.6 \%$ and $26.6 \%$, respectively; $P=0.004$ and $P=0.002$ ).

All of the anti-TNF- $\alpha$ drugs are more effective than placebo in achieving mucosal healing in UC, and they also reduce the number of hospital admissions. ${ }^{52-58}$ Infliximab reduced the cumulative colectomy rate in week $54(10 \%$ versus $17 \%$ placebo; $P=0.0004){ }^{59}$

\section{Comparative efficacy}

Stidham et $\mathrm{al}^{60}$ found that anti-TNF $\alpha$ drugs were superior to placebo in induction and maintenance of remission in UC. No significant differences were recorded between infliximab, adalimumab, and golimumab, and the authors concluded that the choice of drug should be based on cost, safety, administration route, and patient preference. In this meta-analysis, the response and remission rates were greater for infliximab, although statistical significance was not reached.

Another meta-analysis ${ }^{61}$ of the efficacy of biologic drugs (infliximab, adalimumab, golimumab, and vedolizumab) in UC concluded that all of them are superior to placebo in terms of induction of remission, maintenance, and mucosal healing. The meta-analysis provided indirect evidence of the superiority of infliximab versus adalimumab in terms of induction of remission and clinical response. Specifically, the response/remission rate vs. placebo was 4.13 odds ratio, 4.13 (95\% CI 2.39-7.16)/odds ratio, 5.33 (95\% CI 2.28-13.63) with infliximab and odds ratio, 1.76 (95\% CI 1.19-2.56)/odds ratio, 1.91 (95\% CI 0.98-3.72) with adalimumab. 


\section{Combination therapy in $C D$ and $U C$}

The SONIC trial indicates that the combination of azathioprine and infliximab is more effective than either drug in monotherapy for achieving corticosteroid-free remission in moderate to severe $\mathrm{CD} .{ }^{26}$ The mucosal healing rate was higher in the combination therapy group. The infliximab trough levels were higher in the combined treatment group. The problem with combination therapy is the increase of adverse events.

The combination of infliximab and methotrexate did not appear to be superior to infliximab in monotherapy, although anti-TNF $\alpha$ drug levels were higher. ${ }^{34}$ In UC, the SUCCESS study $^{62}$ demonstrated that combination therapy was more effective (response rate 39.7\%) than monotherapy with infliximab (22.1\%) or azathioprine (23.7\%). The mucosal healing rate in week 16 was higher in the combination therapy group.

\section{Biosimilar drugs}

Upon expiry of the patent covering infliximab in 2013, the European Medicines Agency authorized a drug biosimilar to infliximab, ie, CTP-13, an IgG1 type chimeric monoclonal antibody (murine-human), which has not been approved by the US Food and Drug Administration. However, two drugs biosimilar to infliximab are found on the market, ie, Remsima (Celltrion Inc., Incheon, Korea) and Inflectra (Hospira, Lake Forest, CA, USA). Biosimilar drugs are required to have the same pharmacologic presentation, dosage, and administration route as the reference biologic drug. ${ }^{63}$

The European Medicines Agency approved CTP-13 for the treatment of IBD in children and adults, following extrapolation of the efficacy, safety, and pharmacokinetic results for CTP-13 in ankylosing spondylitis and rheumatoid arthritis. ${ }^{63,64}$ The European Crohn's and Colitis Organization has published a position document on the use of biosimilar drugs in IBD. ${ }^{64}$ The main advantage of such drugs is the cost savings they offer for health care systems, while their main inconvenience for clinicians is the lack of knowledge regarding their immunogenicity, exchangeability, and automatic substitution.

\section{Loss of response and optimization} of treatment with anti-TNF $\alpha$ drugs

The efficacy of anti-TNF $\alpha$ drugs in the treatment of IBD is far from optimum. In the clinical trials, patients with the highest response rates had higher drug levels..$^{65,66}$ All biologic drugs are able to induce production of antibodies targeted against them (anti-drug antibodies). ${ }^{67}$ Patients with anti-drug antibodies have lower plasma drug concentrations, increased drug clearance, and more adverse reactions. In this sense, monitoring of biologic drug levels (therapeutic drug monitoring) in blood is an effective tool in management of loss of response to biologic agents. Two situations are found in clinical practice, ie, primary non-responders and patients who lose their response over time (secondary loss of response). In the clinical trials, the primary non-response rate is $10 \%-40 \%$, and clinical remission is not achieved in $50 \%-80 \%$ of patients. The results are better, at $10 \%-20 \%$, in the clinical series. A higher proportion of primary nonresponders is seen in patients with moderate-severe UC flare-ups than in those with $\mathrm{CD} .^{67,68}$

The definition of primary non-response depends on the context in which it is evaluated. Trials establish a primary remission objective (variable, depending on the design), and primary non-responders are regarded as those patients who fail to reach this objective. In clinical series, primary non-responders are patients who fail to respond to two drug infusions on average.$^{68}$ However, other authors consider that we cannot speak of primary non-response until the patients have completed full drug induction. Recently, aiming to unify criteria, another definition of primary non-response has been proposed, ie, lack of improvement in signs of active inflammation (objectively assessed at the start of the study) following the induction phase, despite the presence of adequate drug concentrations and the absence of antibodies against the drug. ${ }^{69}$ Although primary non-response to antiTNF $\alpha$ drugs has been attributed to inflammation being caused through another pathway in such patients, Papamichael et $a l^{69}$ have suggested a more complex mechanism (factors dependent on the drug, the patient, the disease, and/or the treatment strategy used). Traditionally, it has been suggested that switching primary non-responders to a second or third anti-TNF $\alpha$ drug is effective in clinical practice.$^{69}$ Knowing the plasma drug concentration and the anti-drug antibody profile in primary non-responders might offer clues to the origin of the lack of response.

Secondary loss of response has been defined as reappearance of clinical symptoms in patients found to be asymptomatic following induction, due to the inflammatory activity of IBD. ${ }^{67}$ Among responders to infliximab, 37\% lose their response over the years, the annual loss of response rate being $10 \% \cdot{ }^{68}$ In the review by Ben-Horin et al ${ }^{68}$ if loss of response is measured as need to intensify the anti-TNF $\alpha$ drug dose, the figures are in the order of $23 \%-46 \%$ for infliximab and adalimumab, respectively; in contrast, if the criterion used is suspension of anti-TNF $\alpha$ treatment, these range drops to $7 \%-25 \%$. In this 
situation, we must confirm that the gastrointestinal symptoms are effectively attributable to IBD, with the exclusion of other processes. ${ }^{67,68}$ Further, when using subcutaneous treatment, we must confirm patient adherence to therapy.

Production of anti-drug antibodies is influenced by the structure of the biologic drug, the immune status of the patient, the concomitant medication used, and the administration route and dose. Therapeutic drug monitoring and measurement of antibody levels are advised in order to establish a firm diagnosis of loss of response and optimize biologic treatment. This strategy has not been implemented in the guidelines. A strategy for optimizing response in secondary non-responders is shown in Figure 2.

\section{Safety of anti-TNF $\alpha$ drugs}

Anti-TNF $\alpha$ drugs can give rise to a range of adverse events, which require treatment suspension in $10 \%$ of cases. ${ }^{28}$ There have been reports of infusion reactions associated with infliximab (incidence 3\%-17\%), although such reactions proved to be serious in only $1 \%$ of cases. ${ }^{33}$

Opportunistic infections are among the most important adverse events (3\%). The TREAT and ENCORE registries ${ }^{70,71}$ found infliximab to be associated with a risk of such infections (odds ratio 1.43; 95\% CI 1.1-1.84; $P=0.006$ ), although neither infliximab nor IMM therapy increased patient mortality. In addition to use of infliximab, factors associated with the risk of severe opportunistic infections were reported to be severity of disease and use of prednisone and narcotics. ${ }^{72}$ Melanoma is more frequent in CD patients treated with antiTNF $\alpha$ agents (odds ratio 1.3; 95\% CI 1-0-1.6). ${ }^{33}$ Anti-TNF $\alpha$ monotherapy has been associated with a discrete increase in the risk of lymphoma; this risk increases when such drugs are combined with thiopurines. ${ }^{24,33}$ Monotherapy is therefore advised whenever possible.

Anti-TNF $\alpha$ drugs have been shown to increase perioperative complications, especially in $\mathrm{CD}{ }^{33}$ The large registries

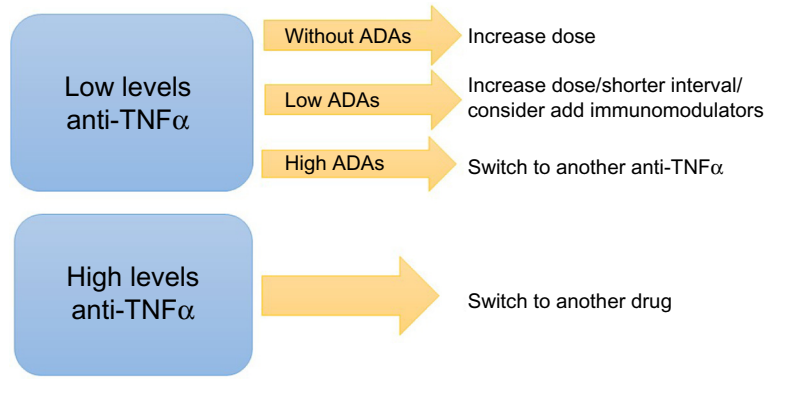

Figure 2 Optimization strategy for non-responders to anti-TNF $\alpha$. Abbreviations: ADAs, anti-drug antibodies; TNF $\alpha$, tumor necrosis factor alpha. indicate that anti-TNF $\alpha$ drugs are not associated with an increased mortality risk, although there have been recent reports of increased mortality in the elderly. ${ }^{28,70}$ These drugs are safe during pregnancy. ${ }^{9,10}$

\section{Ustekinumab}

Ustekinumab is a fully humanized $\operatorname{IgG\kappa }$ monoclonal antibody targeted to the p40 subunit of interleukin-12 and interleukin-23, thereby blocking their biologic activity. ${ }^{73}$ CERTIFI was a randomized, double-blind, placebocontrolled Phase IIb study that analyzed the efficacy of ustekinumab. ${ }^{74}$ The results were statistically significant at an intravenous dose of $6 \mathrm{mg} / \mathrm{kg}$ versus placebo $(39.7 \%$ versus $23.5 \% ; P=0.005)$. For maintenance therapy responders were randomized to $90 \mathrm{mg}$ subcutaneously every 8 weeks or placebo. The clinical response and remission rates were assessed in week 22 . In total, $41.7 \%$ of patients treated with ustekinumab showed clinical remission versus $27.4 \%$ of those given placebo $(P=0.03)$, while the clinical response rates were $69.5 \%$ and $42.5 \%$, respectively $(P<0.001)$. In those who responded to induction, ustekinumab was significantly superior to placebo in terms of both remission and response. The safety profile was found to be similar to that of other biologic agents. At present, a Phase III trial is in progress. ${ }^{75}$

\section{Integrin antagonists Natalizumab}

Natalizumab is a humanized IgG4 monoclonal antibody targeted to the leukocyte integrins $\alpha 4 \beta 1$ and $\alpha 4 \beta 7$. ENACT-1 and ENACT-2 evaluated the efficacy of the drug in induction of remission and maintenance in patients with active CD. ${ }^{76} \mathrm{It}$ was found to be superior to placebo in terms of response and remission, although statistical significance was not reached. ENCORE $^{77}$ has demonstrated its efficacy in controlling active $\mathrm{CD}$, particularly in patients with high $\mathrm{C}$-reactive protein levels. Because of its association with progressive multifocal leukoencephalopathy, ${ }^{78}$ natalizumab has been used as a second-line molecule in CD refractory to therapy, including anti-TNF $\alpha$ drugs, although it has not been approved by the European Medicines Agency.

\section{Vedolizumab}

Approved in 2014 by the US Food and Drug Administration and European Medicines Agency for the treatment of IBD, vedolizumab is a fully humanized monoclonal antibody targeted to leukocyte integrin $\alpha 4 \beta 7$. It selectively inhibits the binding of $\alpha 4$ and $\beta 7$ to MAdCAM-1. Since the drug does 


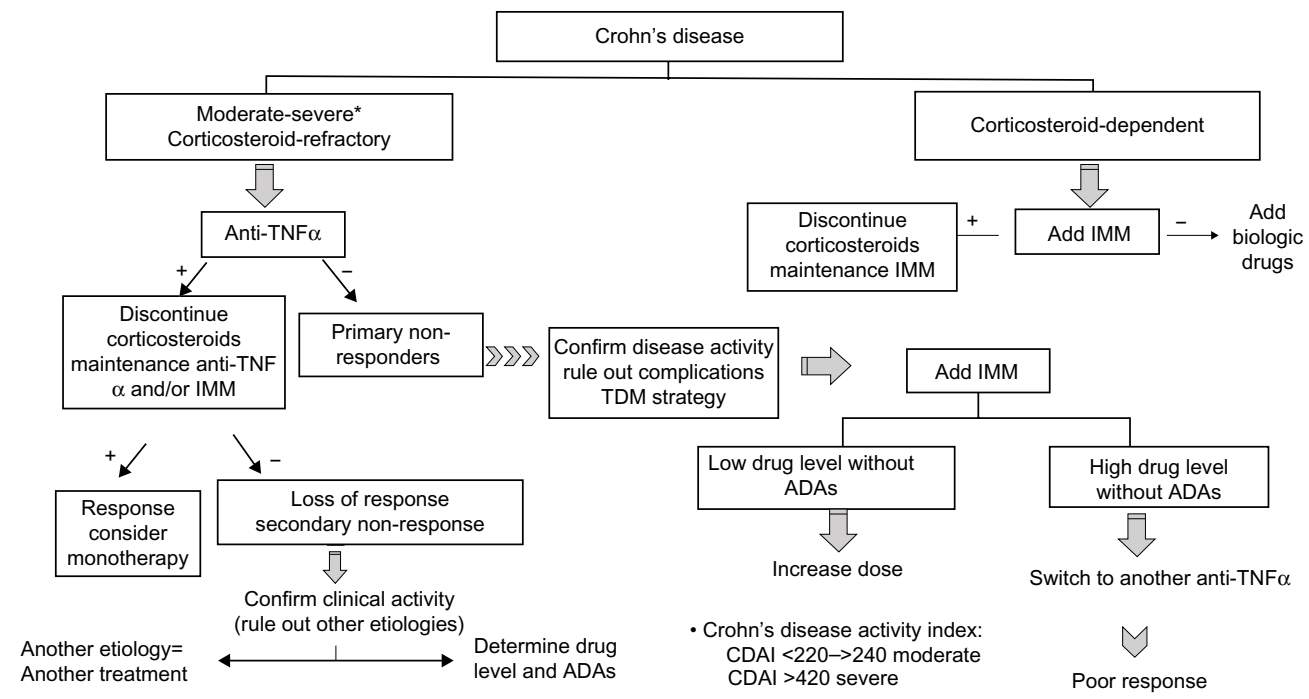

Figure 3 Therapheutic algorithm in Crohn's Disease.

Note: *Indicates low drug level without ADA.

Abbreviations: ADAs, anti-drug antibodies; CDAl, Crohn's Disease Activity Index; IMM, immunomodulator; TDM, therapeutic drug monitoring; TNF $\alpha$, tumor necrosis factor alpha.

not interact with VCAM1, its action is exclusively confined to the bowel. ${ }^{79}$

\section{Efficacy in UC}

GEMINI- $1^{80}$ has shown vedolizumab to be more effective than placebo in inducing and maintaining clinical remission in patients with active UC. In the induction phase (vedolizumab $300 \mathrm{mg}$ intravenously at weeks 0 and 2), the clinical response rate was $47.1 \%$ versus $25.5 \%$ for placebo in week $6(P<0.001)$. In maintenance therapy, the remission rate in week 52 was $41.8 \%$ in patients administered vedolizumab every 8 weeks versus $44.8 \%$ in the group administered vedolizumab every 4 weeks. In turn, $40.9 \%$ of patients receiving vedolizumab showed mucosal healing versus $24.8 \%$ of those given placebo $(P=0.001)$.

\section{Efficacy in CD}

GEMINI-2 evaluated the efficacy of vedolizumab (at the same dose and schedule as in GEMINI-1) for induction and maintenance in patients with active $\mathrm{CD} .{ }^{81}$ The results show superiority of vedolizumab versus placebo in terms of clinical remission in week $6(14.5 \%$ in the vedolizumab group versus $6.8 \%$ in the placebo group: $P=0.02$ ); in week 52 , of those who responded to induction, $39 \%$ and

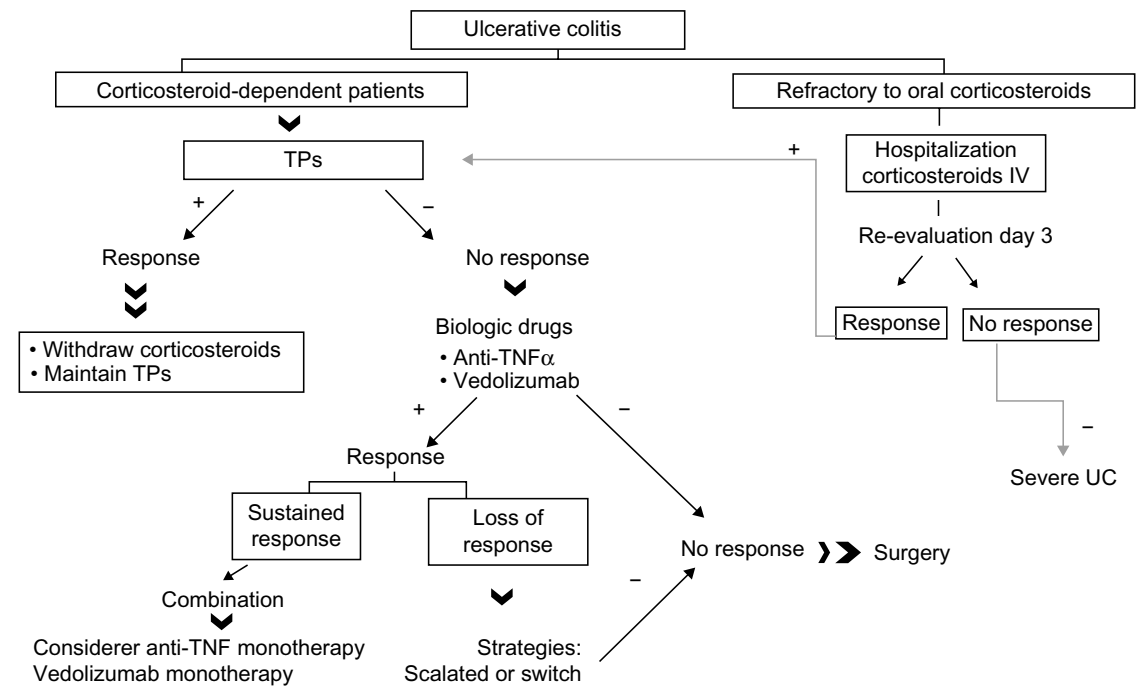

Figure 4 Therapeutic algorithm in ulcerative colitis.

Abbreviations: IV, intravenous; TNF $\alpha$, tumor necrosis factor alpha; UC, ulcerative colitis; TPs, thiopurines. 


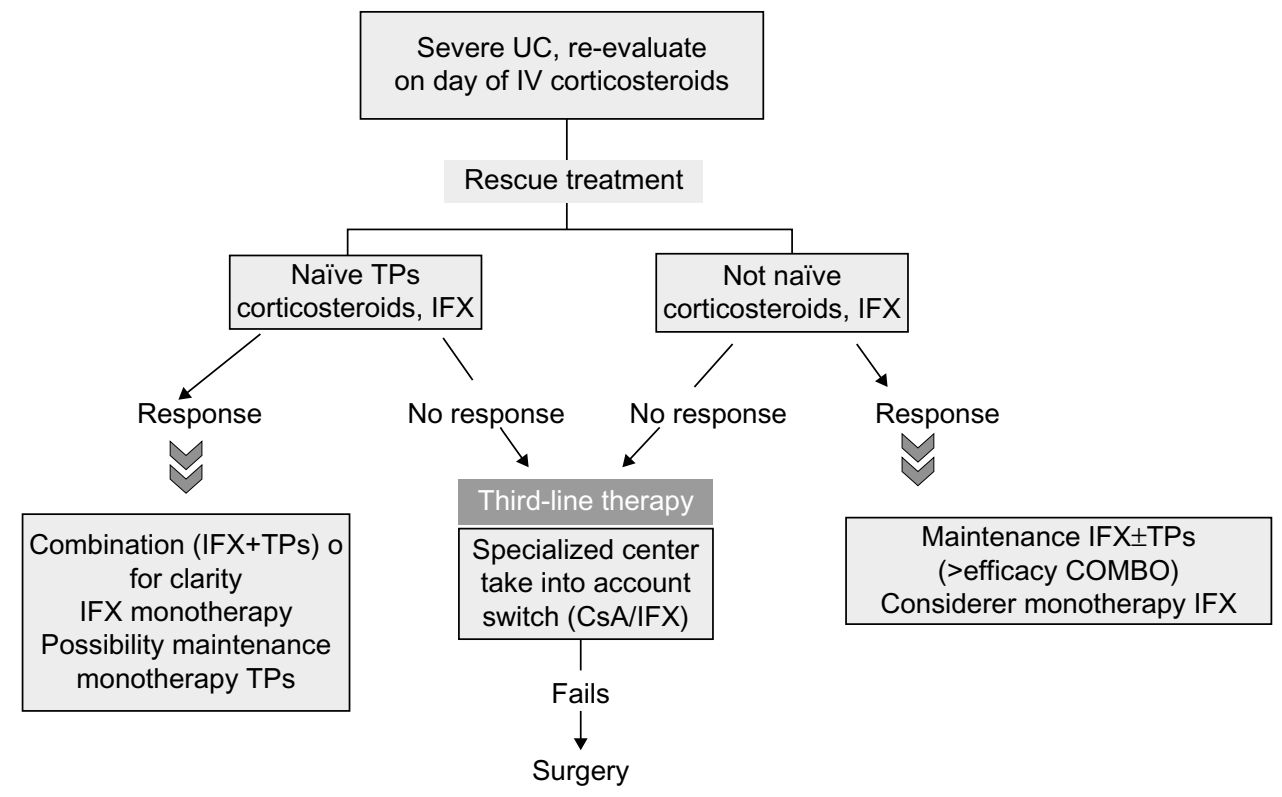

Figure 5 Therapeutic algorithm in severe ulcerative colitis.

Abbreviations: CsA, cyclosporine; IV, intravenous; IFX, infliximab; TPs, thiopurines; UC, ulcerative colitis.

$36.4 \%$ maintained remission (maintenance every 8 and 4 weeks, respectively) versus $21.6 \%$ of those on placebo $(P<0.001$ and $P=0.004)$. GEMINI-3 study found that use of vedolizumab was not more effective than placebo in terms of induction of remission at week 6 in CD patients unresponsive to infliximab. ${ }^{82}$ In sum, the GEMINI trials suggest that vedolizumab is an alternative treatment for patients with CD or UC.

The safety profile was found to be acceptable, with no cases of progressive multifocal leukoencephalopathy, although longer-term studies are needed in this respect. ${ }^{79}$ The therapeutic algorithms for corticosteroid-refractory IBD are shown in Figures 3-5.

\section{Stem cell therapy}

There are two types of stem cell therapy that can be used in IBD, ie, autologous or allogenic hematopoietic stem cell transplantation (HSCT) and mesenchymal stem cells. Allogenic HSCT would correct the genetic defects of the immune system, but is not accepted for IBD due to adverse events. $^{83}$

Autologous HSCT has been used in severe CD for nonresponders to medical treatment in whom surgery is unable to solve the problem due to localization and extent of lesions. ${ }^{84}$ The results have now been published for the randomized, controlled, Phase III ASTIC trial, which included patients with severe $\mathrm{CD}$ treated using autologous HSCT. ${ }^{85}$ The results indicate that HSCT appears to be effective in CD, achieving mucosal healing in $22.7 \%$ of patients, which was maintained on the following year. ${ }^{85}$ This treatment is not free of adverse events, so must be provided at specialized centers.

Mesenchymal stem cells have been used in IBD due to their reparatory and immune-modulating properties. ${ }^{84} \mathrm{~A}$ conditioning cytotoxic regimen prior to transplant is not necessary with mesenchymal stem cells. Evidence in UC is less consistent than in $\mathrm{CD} .{ }^{86}$ It is difficult to draw conclusions because studies are not homogeneous with regard to cell type or the doses administered. Mesenchymal stem cells are a safe therapy with no toxic effects or generation of ectopic tissue. ${ }^{87}$

\section{Disclosure}

Martínez-Montiel, Casis-Herce, Gómez-Gómez, MasedoGonzález, Yela-San Bernardino, Piedracoba, and CastellanoTortajada have no relevant affiliations or financial involvement with any organization or entity which has financial interest in this work. Martínez-Montiel, Casis-Herce, Gómez-Gómez, Masedo-González, and Yela-San Bernardino have acted as advisors to Abbvie, MSD, Shire, and Ferring. The authors alone are responsible for the content and writing of the paper. The authors report no other conflicts of interest in this work.

\section{References}

1. D'Haens GR, Pannacione R, Higgins P, et al. The London Position Statement of the World Congress of Gastroenterology on biological therapy for IBD with the European Crohn's and Colitis Organization: when to start, when to stop, which drug choose, and how to predict response? Am J Gastroenterol. 2011;106:199-212. 
2. Rutgeerts P, Diamond RH, Bala M, et al. Scheduled maintenance treatment with infliximab is superior to episodic treatment for the healing of mucosal ulceration associated with Crohn's disease. Gastrointest Endosc. 2006;63:433-442.

3. Hanauer SB, Feagan BG, Lichtenstein GR, et al. Maintenance infliximab for Crohn's disease: the ACCENT I randomised trial. Lancet. 2002; 359:1541-1549.

4. Baert F, Moortgat L, van Assche G, et al; Belgian Inflammatory Bowel Disease Research Group; North-Holland Gut Club. Mucosal healing predicts sustained clinical remission in patients with early-stage Crohn's disease. Gastroenterology. 2010;138:463-468.

5. Zallot C, Peyrin-Biroulet. Deep remission in inflammatory bowel disease: looking beyond symptoms. Curr Gastroenterol Rep. 2013; 15:315-322.

6. Pariente B, Cosnes J, Danese S, et al. Development of the Crohn's disease digestive damage score, The Lémann score. Inflamm Bowel Dis. 2011;17:1415-1422.

7. Ordás I, Feagan BG, Sandborn WJ. Early use of immunosuppressive or TNF antagonists for the treatment of Crohn's disease: time for a change. Gut. 2011;60:1754-1763.

8. Faubion WA Jr, Loftus EV Jr, Harmsen WS, Zinsmeister AR, Sandborn WJ. The natural history of corticosteroid therapy for inflammatory bowel disease: a population-based study. Gastroenterology. 2001;121:255-260.

9. Dignass A, Van Assche G, Lindsay JO, et al; European Crohn's and Colitis Organisation (ECCO). The Second European evidence-based consensus on the diagnosis and management of Crohn's disease. Current management. J Crohns Colitis. 2010;4:28-62.

10. Dignass A, Lindsay J, Sturm A, et al. Second European evidencebased consensus on the diagnosis and management of ulcerative colitis part 2: current management. J Crohns Colitis. 2012;6: 991-1030.

11. Bär F, Sina C, Fellermann K. Thiopurines in inflammatory bowel disease. World J Gastroenterol. 2013;19:1699-1706.

12. Chande N, Tsoulis DJ, MacDonald JK. Azathioprine or 6-mercaptopurine for induction of remission in Crohn's disease. Cochrane Database Syst Rev. 2013;4:CD000545.

13. Khan KJ, Dubinsky MC, Ford AC, et al. Efficacy of immunosuppressive therapy for inflammatory bowel disease: a systematic review and metaanalysis. Am J Gastroenterol. 2011;106:630-642.

14. Chatu S, Subramanian V, Saxena S, Pollok RC. The role of thiopurines in reducing the need for surgical resection in Crohn's disease. Am J Gastroenterol. 2014;109:23-34.

15. D'Haens G, Geboes K, Rutgeerts P. Endoscopic and histologic healing of Crohn's ileo- colitis with azathioprine. Gastrointest Endosc. 1999;50:667-671.

16. Nielsen $\mathrm{OH}$, Coskun M, Steenholdt C, Rogler G. The role and advances of immunomodulator therapy for inflammatory bowel disease. Expert Rev Gastroenterol Hepatol. 2015;9:177-189.

17. Timmer A, McDonald JW, Tsoulis DI, MacDonald JK. Azathioprine and 6-mercaptopurine for maintenance of remission in ulcerative colitis. Cochrane Database Syst Rev. 2012;9:CD000478.

18. Gisbert JP, Linares PM, McNichollAG, Mate J, Gomollón F. Meta-analysis: the efficacy of azathioprine and mercaptopurine in ulcerative colitis Aliment Pharmacol Ther. 2009;30:126-137.

19. Chhaya V, Saxena S, Cecil E, et al. The impact of timing and duration of thiopurine treatment on colectomy in ulcerative colitis: a national population-based study of incident cases between 1989-2009. Aliment Pharmacol Ther. 2015;41:87-98.

20. Chaparro M, Ordás I, Cabre E, et al. Safety of thiopurine therapy in inflammatory bowel disease: long-term follow-up study of 3931 patients. Inflamm Bowel Dis. 2013;19:1404-1410.

21. Rahier JF, Magro F, Abreu C, et al. Second European evidence-based consensus on the prevention, diagnosis and management of opportunistic infections in inflammatory bowel disease. European Crohn's and Colitis Organization (ECCO). J Crohns Colitis. 2014;8:443-468.
22. Kotlyar DS, Lewis JD, Beaugerie L, et al. Risk of lymphoma among inflammatory bowel disease patients treated with azathioprine and 6-mercaptopurine: a meta-analysis. Clin Gastroenterol Hepatol. 2015; 13:847-858. e4.

23. Dulai PS, Siegel CA, Colombel JF, Sandborn W, Peyrin-Biroulet L. Systematic review: monotherapy with antitumour necrosis factor $\alpha$ agents versus combination therapy with an immunosuppressive for IBD. Gut. 2014;63:1843-1853.

24. Beaugerie L. Immunosuppression-related lymphomas and cancers in IBD: how can they be prevented? Dig Dis. 2012;30:415-419.

25. Louis E, Irving P, Beaugerie L. Use of azathioprine in IBD: modern aspects of and old drug. Gut. 2014;63:1695-1699.

26. Colombel JF, Sandborn WJ, Reinisch W, et al; SONIC Study Group. Infliximab, azathioprine, or combination therapy for Crohn's disease. N Engl J Med. 2010;362:1383-1395.

27. Kennedy NA, Kalla R, Warner B, et al. Thiopurine withdrawal during sustained clinical remission in inflammatory bowel disease: relapse and recapture rates, with predictive factors in 237 patients. Aliment Pharmacol Ther. 2014;40:1313-1323.

28. Bryant RV, Brain O, Travis SP. Conventional drug therapy for inflammatory bowel disease. Scand J Gastroenterol. 2015;50:90-112.

29. Swaminath A, Taunk RJ, Lawlor G. Use of methotrexate in inflammatory bowel disease in 2014: a user's guide. World J Gastrointest Pharmacol Ther. 2014;5:113-121.

30. McDonald JW, Wang Y, Tsoulis DJ, McDonald JK, Feagan BG. Methotrexate for induction of remission in refractory Crohn's disease. Cochrane Database Syst Rev. 2014;6:CD003459.

31. Patel V, Wang Y, McDonald JK, McDonald JW, Chande N. Methotrexate for maintenance of remission in Crohn's disease. Cochrane Database Syst Rev. 2014;8:CD006884.

32. Ardizzone S, Bollani S, Manzionna G, et al. Comparison between methotrexate and azathioprine in the treatment of chronic active Crohn's disease: a randomized, investigator-blind study. Dig Liver Dis. 2003;35:619-627.

33. Mclean LP, Cross RK. Adverse events in IBD: to stop or continue immune suppressant and biological treatment. Expert Rev Gastroenterol Hepatol. 2014;8:223-240.

34. Feagan BG, McDonald JW, Pannacione R, et al. Methotrexate in combination with infliximab is no more effective than infliximab alone in patients with Crohn's disease. Gastroenterology. 2014;146:681-688.

35. Farkas K, Molnár T, Szepes Z. Ability of different rescue therapies to save the bowel in acute, severe, steroid-refractory ulcerative colitis. Expert Rev Gastroenterol Hepatol. 2014;8:695-702.

36. Nelson R, Liao C, Fichera A, Pekow J. Rescue therapy with cyclosporine or infliximab is not associated with an increased risk for postoperative complications in patients hospitalized for severe steroid-refractory ulcerative colitis. Inflamm Bowel Dis. 2014;20:14-20.

37. Chang KH, Burke JP, Coffey JC. Infliximab versus cyclosporine as rescue therapy in acute severe steroid-refractory ulcerative colitis: a systematic review and meta-analysis. Int J Colorectal Dis. 2013;28: 287-293.

38. McDonald JW, Feagan BG, Jewell D, Brynskow J, Stange EF, McDonald JK. Cyclosporine for induction of remission in Crohn's disease. Cochrane Database Syst Rev. 2005;2:CD000297.

39. McSharry K, Dalzell AM, Leiper K, El-Matary W. Systematic review: the role of tacrolimus in the management of Crohn's disease. Aliment Pharmacol Ther. 2011;34:1282-1294.

40. Smith MR, Cooper SC. Mycophenolate mofetil therapy in the management of inflammatory bowel disease: a retrospective case series and review. J Crohns Colitis. 2014;8:890-897.

41. Gerich ME, Yoon JL, Targan SR, Ippolti AF, Vasiliauskas EA. Long-term outcomes of thalidomide in refractory Crohn's disease. Aliment Pharmacol Ther. 2015;41:429-437.

42. Sands BE, Anderson FH, Bernstein CN, et al. Infliximab maintenance therapy for fistulizing Crohn's disease. $N$ Engl J Med. 2004;350: $876-885$. 
43. Lichtenstein GR, Yan S, Bala M, Blank M, Sands BE. Infliximab maintenance treatment reduces hospitalizations, surgeries, and procedures in fistulizing Crohn's disease. Gastroenterology. 2005;128: $826-829$.

44. Hanauer SB, Sandborn WJ, Rutgeerts P, et al. Human anti-tumor necrosis factor monoclonal antibody (adalimumab) in Crohn's disease: the CLASSIC-I trial. Gastroenterology. 2006;130:323-333.

45. Sandborn WJ, Hanauer SB, Rutgeerts P, et al. Adalimumab for maintenance treatment of Crohn's disease: results of CLASSIC II trial. Gut. 2007;56:1232-1239.

46. Colombel JF, Sandborn WJ, Rutgeerts P, et al. Adalimumab for maintenance of clinical response and remission in patients with Crohn's disease: CHARM trial. Gastroenterology. 2007;132:52-65.

47. Colombel JF, Rutgeerts P, Sandborn WJ, et al. Deep remission for adalimumab-treated patients with moderate to severe ileocolonic Crohn's disease: results from EXTEND. J Crohns Colitis. 2010:138:S158.

48. Sandborn WJ, Rutgeerts P, Enns R, et al. Adalimumab induction therapy for Crohn's previously treated with infliximab: a randomized trial. Ann Intern Med. 2007;146:829-838.

49. Schreiber S. Certolizumab pegol for the treatment of Crohn's disease. Therap Adv Gastroenterol. 2011;4:375-389.

50. Da W, Zhu J, Wang L, Lu Y. Efficacy and safety of certolizumab pegol from Crohn's disease: a systematic review and meta-analysis. Adv Ther. 2013;30:541-553.

51. Stidham RW, Lee TC, Higgins PD, et al. Systematic review with network meta-analysis: the efficacy of anti-TNF agents for the treatment of Crohn's disease. Aliment Pharmacol Ther. 2014;39: 1349-1362.

52. Rutgeerts P, Sandborn WJ, Feagan BG, et al. Infliximab for induction and maintenance therapy for ulcerative colitis. $N$ Engl J Med. 2005;353: 246-276.

53. Lawson MM, Thomas AG, Akobeng AK. Tumor necrosis factor alpha blocking agents for induction of remission in ulcerative colitis. Cochrane Database Syst Rev. 2006;3:CD005112.

54. Järnerot G, Hertevig E, Friis-Liby I, et al. Infliximab as rescue therapy in severe ulcerative colitis: a randomized, placebo-controlled study. Gastroenterology. 2005;128:1805-1811.

55. Reinisch W, Sandborn WJ, Hommes DW, et al. Adalimumab for induction of clinical remission in moderately to severe active ulcerative colitis: results of randomized controlled trial. Gut. 2011;60: 780-787.

56. Sandborn WJ, van Assche G, Reinisch W, et al. Adalimumab induces and maintains clinical remission in patients with moderate-to-severe active ulcerative colitis. Gastroenterology. 2012;142:257-265.

57. Sandborn WJ, Feagan BG, Marano C, et al; PURSUIT-SC Study Group. Subcutaneous golimumab induces clinical response and remission in patients with moderate-to-severe ulcerative colitis. Gastroenterology. 2014;146:85-95.

58. Sandborn WJ, Feagan BG, Marano C, et al; PURSUIT-Maintenance Study Group. Subcutaneous golimumab maintains clinical response in patients with moderate-to-severe ulcerative colitis. Gastroenterology. 2014; 146:96-109.

59. Sandborn WJ, Rutgeerts P, Feagan BG, et al. Colectomy rate comparison after treatment of ulcerative colitis with placebo or infliximab. Gastroenterology. 2009;137:1250-1260.

60. Stidham RW, Lee TC, Higgins PD, et al. Systematic review with network meta-analysis: the efficacy of anti-tumour necrosis factor-alpha agents for the treatment of ulcerative colitis. Aliment Pharmacol Ther. 2014;39:660-671.

61. Danese S, Fiorino G, Peyrin-Biroulet L, et al. Biological agents for moderately to severe active ulcerative colitis. A systematic review and network meta-analysis. Ann Intern Med. 2014;160:704-711.

62. Panaccione R, Gosh S, Middleton S, et al. Combination therapy with infliximab and azathioprine is superior to monotherapy with infliximab and azathioprine is superior to monotherapy with either agent in ulcerative colitis. Gastroenterology. 2014;146:392-400. e3.
63. Rinaudo-Gaujous M, Paul S, Tedesco ED, Genin C, Roblin S, Peyrin-Biroulet L. Review article: are the next generation of drugs for liver and gastrointestinal disease. Aliment Pharmacol Ther. 2013;38: 914-924.

64. Danese S, Gomollon F; Governing Board and Operational Board of ECCO. The use of biosimilar medicines in the treatment of inflammatory bowel disease (IBD). J Crohns Colitis. 2013;7:586-589.

65. Seow $\mathrm{CH}$, Newman A, Irwin S, Steinhart A, Silverberg M, Greenberg G. Trough serum infliximab: a predictive factor of clinical outcome for infliximab treatment in acute ulcerative colitis. Gut. 2010;59:49-54.

66. Chiu IL, Rubin DT, Vermiere S, et al. Serum adalimumab concentration and clinical remission in patients with Crohn's disease. Inflamm Bowel Dis. 2013;19:1112-1122.

67. Kopylov U, Ben-Horin S, Seidman E. Therapeutic drug monitoring in inflammatory bowel disease. Ann Gastroenterol. 2014;27;304-312.

68. Ben-Horin S, Kopylov U, Chowers Y. Optimizing anti-TNF treatments in inflammatory bowel disease. Autoimmun Rev. 2014;13:24-30.

69. Papamichael K, Gils A, Rutgeerts P, et al. Role for therapeutic drug monitoring during induction therapy with TNF antagonists in IBD: evolution in the definition and management of primary nonresponse. Inflamm Bowel Dis. 2015;21:182-197.

70. Lichtenstein GR, Feagan BG, Cohen RD, et al. Serious infections and mortality in association with therapies for Crohn's disease: TREAT registry. Clin Gastroenterol Hepatol. 2006;6:621-630.

71. D'Haens G, Colombel JF, Hommes DW, et al. Corticosteroids pose an increased risk for serious infection: an interim safety analysis of the ENCORE Registry. Gastroenterology. 2008;134 Supp1:A-140.

72. Ford AC, Peyrin-Biroulet L. Opportunistic infections with anti-tumor necrosis factor alpha therapy in inflammatory bowel disease: metaanalysis of randomized controlled trials. Am J Gastroenterol. 2013;108: 1268-1276.

73. Sandborn WJ, Gasink C, Gao L-L, Blank MA, Johanns J, Guzzo C. Ustekinumab induction and maintenance therapy in refractory Crohn's disease. N Engl J Med. 2012;367:1519-1528.

74. Benson JM, Peritt D, Scallon BJ, et al. Discovery and mechanism of ustekinumab a human monoclonal antibody targeting interleukin-12 and interleukin-23 for treatment of immune-mediated disorders. MAbs. 2011;3:535-545.

75. Leiman DA, Lichtenstein GR. Therapy of inflammatory bowel disease: what to expect in the next decade. Curr Opin. 2014;30:385-390.

76. Sandborn WJ, Colombel JF, Enns R, et al. Natalizumab induction and maintenance therapy for Crohn's disease. $N$ Engl J Med. 2005;353: 1912-1925.

77. Targan SR, Feagan BG, Fedorack RN, et al. Natalizumab for the treatment of active Crohn's disease: results of the ENCORE trials. Gastroenterology. 2007;132:1672-1683.

78. Clifford DB, De Luca A, Simpson DM, Arendt G, Nath A. Natalizumabassociated progressive multifocal leukoencephalopathy in patients with multiple sclerosis: lessons from 28 cases. Lancet Neurol. 2010;9: 438-446.

79. Raine T. Vedolizumab for inflammatory bowel disease: changing the game, or more of the same? United European Gastroenterol J. 2014;25: 333-334.

80. Feagan BG, Rutgeerts P, Bruce E, et al. Vedolizumab as induction and maintenance therapy for ulcerative colitis. $N$ Engl J Med. 2013;369: 699-709.

81. Sandborn WJ, Brian G, Feagan BG, et al. Vedolizumab as induction and maintenance therapy for Crohn's disease. N Engl J Med. 2013;369: 711-721.

82. Sands BE, Feagan BG, Rutgeerts P, et al. Effects of vedolizumab induction for patients with Crohn's disease in whom tumor necrosis factor antagonist treatment failed. Gastroenterology. 2014;147:618-627.

83. Leung Y, Geddes M, Storek J, Panaccione R, Beck PL. Hematopoietic cell transplantation for Crohn's disease: is it time? World J Gastroenterol. 2006;12:6665-6673. 
84. Martínez-Montiel MP, Gómez Gómez GJ, Flores AI. Therapy with stem cells in inflammatory bowel disease. World J Gastroenterol. 2014;20: 1211-1227.

85. Hawkey C, Allez M, Ardizzone S, et al. Clinical and endoscopic improvement following hematopoietic stem cell transplantation in the ASTIC trial. J Crohns Colitis. 2013;7:S4.

86. Forbes GM, Sturm MJ, Leong RW, Sparrow MP, Segarajasingam D. A Phase 2 study of allogenic mesenchymal stromal cells for luminal Crohn's disease refractory to biological therapy. Clin Gastroenterol Hepatol. 2014;12:64-71.
87. Lalu MM, McIntyre L, Pugliese C, Ferguson D, Winston BW, Marshall JC. Safety of stromal cells (SafeCell): a systematic review and meta-analysis of clinical trials. PLoS One. 2012;7:e7559.

\section{Publish your work in this journal}

Clinical and Experimental Gastroenterology is an international, peerreviewed, open access journal, publishing all aspects of gastroenterology in the clinic and laboratory, including: Pathology, pathophysiology of gastrointestinal disease; Investigation and treatment of gastointes tinal disease; Pharmacology of drugs used in the alimentary tract;
Immunology/genetics/genomics related to gastrointestinal disease. This journal is indexed on CAS. The manuscript management system is completely online and includes a very quick and fair peer-review system. Visit http://www.dovepress.com/testimonials.php to read real quotes from published authors.

Submit your manuscript here: http://www.dovepress.com/clinical-and-experimental-gastroenterology-journal 